IN 1967 a group of geographers in the US and Canada initiated a study of the human and social responses to natural hazards in different parts of the world. The sort of questions they hoped to answer were: How many people inhabit particular areas of hazard and why do they continue to do so? How do these inhabitants perceive the extreme natural events to which they are subject? What options are open to them, both individually and collectively, in adjusting to the dangers and how are these options exercised? For six years, investigators in more than 23 countries collaborated in interviewing samples of populations at risk from earthquakes in San Francisco, cyclones in Bangladesh, drought in Kenya and Australia, floods in India and Britain, volcanic eruptions in Hawaii, avalanches in Norway, and various other hazards in nations at different stages of development.

The results of this 'loosely coordinated' survey, many of which are described in the 32 articles in Natural Hazards, are disturbing, although perhaps not entirely surprising. Galveston, Texas, is prone to hurricanes; but although most residents of the city are aware of the threat, about a third of them refuse to believe they will ever be affected personally and therefore take no precautions. About a fifth of San Franciscans think they will never experience earthquake damage. Over half of those who live on the River Severn floodplain in Shrewsbury, England, not only do not expect to witness a flood in the future but do not even know they have a flood problem. The list goes on and on; and it all makes fascinating reading.

The point of this study, however, is

\section{Hazards of life}

Natural Hazards: Local, National, Global. Edited by Gilbert F. White. Pp. xvi+288. (Oxford University: New York, London and Toronto, 1975.) £7.50. Geological Hazards: Earthquakes - Tsunamis - Volcanoes - Avalanches - Landslides - Floods. By B. A. Bolt, W. L. Horn, G. A. Macdonald and R. F. Scott. Pp. viii +328. (Springer: Berlin and New York, 1975.) Physical Aspects of Natural Catastrophes. By Adrian E. Scheidegger. Pp. xiii +289. (Elsevier: Amsterdam, Oxford and New York, 1975). Dfl. 70; \$29.25.

not to catalogue human ignorance and irrationality for their own sake but to assess the nature of the real responses with which public policy to mitigate the effects of natural hazards must contend. All too often in the past, technological solutions to the problem of coping with hazards have failed because they were based on costbenefit analyses which assumed that people will always behave in an economically rational way. The cost of flood damage in the US, for example, has continued to increase alarmingly in spite of a multi-billion dollar investment in flood control works spread over more than 20 years. Likewise, hurricane warning systems, however accurate, have been less than completely effective in convincing the public to take avoidance measures. The fact is that real people. given freedom of choice, seldom behave in the tidy way that policy makers would wish. This may be partly through ignorance and vartly through misguided optimism, but it also reflects the existence of more than one scale of human values.

The importance of Natural Hazards is that it gives substance in a particular context to the old allegation that there is nothing so unpredictable as people and points up the folly of those who have persistently ignored this simple fact of life. The book should therefore be essential reading for all those scientists who see complete solutions to the problems of natural hazards in the rational pursuit of scientific knowledge and to all those politicians and administrators who have been misled into believing that all physical and human nature may ultimately be subdued by the technological fix.

But although the scientific approach may not be sufficient to cope with natural hazards, it is certainly necessary, and is given due prominence in Geological Hazards. Presumably the original work of Gilbert F. White and his colleagues is still too new to have reached the secondary texts, and so there is little here about the vagaries of human behaviour. On the other hand, although primarily a book about science, the science is placed firmly in the social context which gives it point. As a general (descriptive and nonmathematical) introduction to a wide range of natural hazards, this book may be recommended without reserve.

With neither the common theme of human response nor the self-justifying interest of the general reader, the linking of different hazards in Physical Aspects of Natural Catastrophes has less point. Intended largely as a scientific source book for engineers, the book is mathematical and utilitarian. It may be referred to, if necessary, but is unlikely to be read.

Peter J. Smith
THE first chapter is devoted to the methods and results of the LCAOMO Hückel approach. Though the first section of this chapter is headed "Orbitals", I feel that a reader of this book would need to know something about atomic and molecular quantum mechanics before he started. It seemed to me surprising to devote so much of the first chapter of a book like this to $\pi$-orbitals, though I think the author is very sensible to use the allyl system as his example.

In the second chapter Zimmerman deals with eigenvalues, eigenfunctions operators and the variation method, which is dealt with clearly at some

\section{Quantum mechanics}

Quantum Mechanics for Organic Chemists. By Howard E. Zimmerman. Pp. $x+215$. (Academic: New York and London, May 1975.) \$16.50; £7.90.

length. The next chapter explains the effects of molecular symmetry and introduces the reader to group theory. After that the book returns to the Hückel method and extends the earlier consideration, continuing with an account of more advanced treatments. Systems are treated as containing many interacting electrons; Slater determinants and the SCF method are described. There is also a description of configuration interaction and examples of its applications.

It is fair to say that this book approaches and tackles the problem of presenting quantum mechanics to organic chemists in a manner different from that used by other books. As such, it is interesting and stimulating; I certainly found it very much worth studying. But I must say also that I was not left convinced that the treatment and sequence used is the best way to tackle the job; but it deserves consideration and parts are well done and most useful.

J. W. Linnett 